Article

\title{
The Effect of Different Concrete Designs on the Life-Cycle Assessment of the Environmental Impacts of Concretes Containing Furnace Bottom-Ash Instead of Sand
}

\author{
Svetlana Pushkar \\ Department of Civil Engineering, Ariel University, Ariel 40700, Israel; svetlanap@ariel.ac.il
}

Received: 8 July 2019; Accepted: 26 July 2019; Published: 29 July 2019

\begin{abstract}
The results of life-cycle assessments (LCAs) of concrete are highly dependent on the concrete design method. In this study, LCAs were conducted to evaluate the environmental impacts of the replacement of sand with furnace bottom-ash (FBA) in concrete. In the FBA-based concretes, sand was replaced with FBA at proportions of $0,30,50,70$, and $100 \mathrm{wt} \%$. Two design methods were studied: (i) concrete with fixed slump ranges of 0-10 $\mathrm{mm}$ (CON-fix-SLUMP-0-10) and 30-60 mm (CON-fix-SLUMP-30-60); and (ii) concrete with fixed water/cement (W/C) ratios of 0.45 (CON-fix-W/C-0.45) and 0.55 (CON-fix-W/C-0.55). The ReCiPe2016 midpoint and single-score (six methodological options) methods were used to compare the environmental damage caused by the FBA-based concretes. A two-stage nested (hierarchical) analysis of variance (ANOVA) was used to simultaneously evaluate the results of six ReCiPe2016 methodologies. The ReCiPe2016 results indicate that replacing sand with FBA decreased the environmental impact of the concretes with fixed slump ranges and increased the environmental impact of the concretes with fixed $\mathrm{W} / \mathrm{C}$ ratios. Therefore, using FBA as a partial sand replacement in concrete production is of debatable utility, as its impact highly depends on the concrete design method used.
\end{abstract}

Keywords: furnace bottom-ash; sand replacement; concrete design method; life-cycle assessment (LCA); ANOVA

\section{Introduction}

In the concrete industry, a common worldwide approach to reducing pollution is the replacement of cement with byproducts from other industries, such as fly ash (FA), furnace coal bottom-ash (FBA), and ground granulated blast furnace slag (GGBS) [1,2]. Such cement replacement has been widely studied in an effort to improve the mechanical performance, and reduce the cost and environmental impact, of byproduct-based concretes in comparison with conventional concretes. Many positive results have been reported in this area. For example, Phul et al. [3] studied the mechanical performance of concrete with between $0 \%$ and $30 \%$ of cement replaced with GGBS and FA, and reported a $26.3 \%$ increase in the compressive strength. Additionally, Meng et al. [4] studied the cost-effectiveness of ultra-high performance concretes (UHPC) with a high volume of cement replaced with Class C fly-ash (FAC), GGBS, and silica fume (SF), and with the complete replacement of quartz sand with conventional concrete sand. They reported that the cost of such mixtures was 4.1-4.5 $\$ / \mathrm{m}^{3} / \mathrm{MPa}$ under standard concrete curing conditions. Furthermore, Saade et al. [5] studied the environmental impacts of concretes with $66 \%$ of cement replaced with GBFS, and reported an approximate $40-70 \%$ decrease in the environmental impacts of the concrete, such as abiotic depletion, acidification, and eutrophication.

However, the depletion of natural aggregates such as gravel and sand is also a current environmental problem [6]. Therefore, studies have investigated the replacement of sand with 
several industrial byproducts, such as FA, FBA, copper slag (CS), and quarry dust powder (QDP) [7-9]. Chowdhury et al. [7] studied the full replacement of sand with FA and FBA in road construction, and reported mixed results: climate change (e.g., $\mathrm{CO}_{2}$ emissions) and environmental acidification were found to be lower for the byproducts, whereas the formation of particulate matter was found to be lower for the sand. Kua [8] performed a life-cycle assessment (LCA) of high-performance concrete in which sand had been partially (10 vol\%) replaced with CS, and reported an increased climate change impact (e.g., increased $\mathrm{CO}_{2}$ emissions) compared to that of conventional concrete. Lim et al. [9] studied the replacement of a high percentage of sand with QDP in lightweight foamed concrete, and reported a decrease in $\mathrm{CO}_{2}$ emissions of up to $10 \%$. This highlights that the effect of the partial or full substitution of sand in the production of concrete is not fully understood and requires additional research.

Among all the possible industrial byproducts, the conversion of waste from coal-fired electricity production into an environmentally friendly byproduct for the production of concrete is a pressing issue for environmentally sustainable development in many countries [2]. For example, Zhang and Poon [10] considered the use of FBA, a waste byproduct from coal-fired electricity production, as an alternative to natural fine aggregates in byproduct-based concrete production to improve the concrete's environmental impact.

The problem of producing concrete with a low environmental impact is also important for Israel. Concrete is a major building material in Israel [11], and furthermore, according to the Israel Electric Corporation Ltd., [12] 50-57\% of Israel's electricity is produced from coal burning. In a recent study [13], $18 \mathrm{wt} \%$ of sand was replaced with FA in concrete produced in Israel, and the authors reported significant improvements in the mechanical and chemical properties of the concrete. However, the environmental impact of concrete in which sand is partially or fully replaced with byproducts from Israeli coal-fired electricity production is unknown. LCA is an appropriate approach to elucidate the trade-offs of such replacements [14]. A key element of LCA is a functional unit (FU) that must be shared by all the compared alternatives and to which all inputs and outputs of the raw materials, and their embodied energies and emissions, should be traced [15].

For a proper comparison of the FUs of concrete alternatives (both conventional and byproduct-based), at least the following parameters should be comparable: (i) fresh properties of the concrete (e.g., the consistency); (ii) hardened properties of the concrete (e.g., the compressive strength); and (iii) the durability of the concrete (e.g., the water penetration). To achieve this, previous LCA studies have used two different concrete $(\mathrm{CON})$ design methods: (i) concrete with a fixed slump range (CON-fix-SLUMP); or (ii) a concrete with a fixed water/cement (W/C) ratio (CON-fix-W/C) [16-18].

Turk et al. [16] used a fixed slump range of 185-205 mm in byproduct-based concretes in which sand had been partially replaced by foundry sand or steel slag and which contained FA as a mineral admixture. These authors showed that the ranges of the 28-day compressive strength and the water penetration depths were 30.1-45.3 MPa and 16-34 mm, respectively. Despite these conditions, the FU included the production of $1 \mathrm{~m}^{3}$ of concrete without normalization to the 28-day compressive strength. Additionally, Turk et al. [16] conducted consequential LCA modeling for the byproducts. This resulted in a reduced global warming potential (GWP), acidification potential, eutrophication potential, and photochemical ozone creation potential for the byproduct-based concretes compared to conventional concretes [16].

Prem et al. [17] compared conventional concretes (control) with byproduct-based concretes in which $100 \mathrm{vol} \%$ of sand had been replaced with CS for fixed W/C ratios of $0.37,0.47$, and 0.57 . The absolute volume method was used when replacing sand with CS. This method limits the addition of any excess water, which can increase the $\mathrm{W} / \mathrm{C}$ ratio and in turn reduce the strength of the concrete. As a result, the CS-based concretes demonstrated an improved strength (compressive and flexural) and durability (chloride permeability and chloride sorptivity) compared with conventional concretes. In the study of Prem et al. [17], the FU of $1 \mathrm{~m}^{3}$ of concrete was not normalized to the 28-day compressive strength. Additionally, byproduct-based concretes showed a higher embodied energy and GWP compared with conventional concretes. In this case, attributive LCA modeling was conducted, 
which entails that the environmental damage from CS production was attributed to the CS-based concretes [17].

Gursel and Ostertag [18] analyzed high-strength byproduct-based concretes in which sand had been replaced by CS at an incremental rate of $20 \mathrm{wt} \%$ (CS0:CS20:CS100) for a fixed W/C ratio of 0.3 . The $\mathrm{FU}$ of $1 \mathrm{~m}^{3}$ of concrete was normalized to the 28-day compressive strength, which was in the range of 65-98 MPa for CS0-SC100 concretes. Significant increases in the embodied energy, GWP, acidification potential, and particulate matter content were found for these concretes compared to conventional concretes. Therefore, to reduce the environmental impact of the concrete, Gursel and Ostertag [18] suggested only replacing up to $40 \%$ of sand with CS.

Based on [16-18], it should be assumed that the environmental impacts of byproduct-based concretes may depend on the selected concrete design method. However, the effect of different concrete designs on the LCAs of byproduct-based concretes with normalization to the 28-day compressive strength has not yet been considered.

Therefore, the aim of this study was to conduct LCAs of the FUs of concrete normalized to the 28-day compressive strength, with the natural material (sand) replaced by a byproduct (FBA) using two design methods: (i) concrete mixtures designed with fixed slump ranges of $0-10 \mathrm{~mm}$ and 30-60 mm (CON-fix-SLUMP); and (ii) concrete mixtures designed with fixed W/C ratios of 0.45 and 0.55 (CON-fix-W/C). For both design methods, the concrete mixtures and properties were based on those described by Bai et al. [19] for the LCAs.

FBA was used as the sand-replacing material since this byproduct has a similar particle distribution to that of sand and a much lower pozzolanic activity than that of FA, which makes FBA less attractive for cement replacement, but appropriate for sand replacements [6,19].

The reason why both fixed-slump concrete and fixed $\mathrm{W} / \mathrm{C}$ ratio concrete were studied is due to the fact that fixed-slump concrete has the same workability as fresh mixture alternatives, while fixed W/C ratio concrete has the same compressive strength as hard concrete alternatives. Moreover, it has been reported in the literature that using these different design methods for FBA-based concrete (in which sand was replaced with FBA) leads to different mechanical properties, such as compressive strength and drying shrinkage [6,19]. Therefore, this study investigated the influence of fixed-slump and fixed W/C FBA-based concrete design methods on the environmental impact of concrete.

\section{Materials and Methods}

\subsection{Concrete Mixture Designs}

The LCAs of five FBA-based concrete alternatives with $0,30,50,70$, and $100 \mathrm{wt} \%$ of sand replaced with FBA were evaluated. The alternatives were denoted as FBA0, FBA30, FBA50, FBA70, and FBA100, respectively. The components of the concrete alternatives were based on those described by Bai et al. [19], who designed four concrete mixtures according to (i) a fixed slump range (0-10 mm and $30-60 \mathrm{~mm}$ ) and (ii) a fixed $\mathrm{W} / \mathrm{C}$ ratio $(0.45$ and 0.55$)$ and evaluated the compressive strength and drying shrinkage of the resultant concretes (Tables 1-4). For these concrete mixtures, Table 5 presents the particle distribution of sand and FBA and Table 6 presents the chemical composition of FBA [19]. In the present study, the concretes with fixed slump ranges of $0-10 \mathrm{~mm}$ and $30-60 \mathrm{~mm}$ were denoted as CON-fix-SLUMP-0-10 and CON-fix-SLUMP-30-60, respectively (Tables 1 and 2, respectively), while the concretes with fixed W/C ratios of 0.45 and 0.55 were denoted as $\mathrm{CON}$-fix-W/C-0.45 and CON-fix-W/C-0.55, respectively (Tables 3 and 4, respectively). 
Table 1. CON-fix-SLUMP-0-10: concrete mixture design with a fixed slump range of 0-10 mm and the concrete's properties (based on Bai et al. [19]).

\begin{tabular}{cccccc}
\hline Material/property & FBA0 $_{\text {SL0-10 }}$ & FBA30 $_{\text {SL0-10 }}$ & FBA50 $_{\text {SL0-10 }}$ & FBA70 $_{\text {SL0-10 }}$ & FBA100 $_{\text {SL0-10 }}$ \\
\hline Portland cement & 382 & 382 & 382 & 382 & 382 \\
$\left(\mathrm{~kg} / \mathrm{m}^{3}\right)$ & 199 & 168 & 145 & 126 & 103 \\
Water content $\left(\mathrm{kg} / \mathrm{m}^{3}\right)$ & 625 & 380 & 251 & 141 & 0 \\
Sand $\left(\mathrm{kg} / \mathrm{m}^{3}\right)^{1}$ & 0 & 163 & 251 & 328 & 424 \\
FBA $\left(\mathrm{kg} / \mathrm{m}^{3}\right)^{1}$ & 1270 & 1327 & 1371 & 1407 & 1450 \\
$\begin{array}{c}\text { Coarse aggregate } \\
\left(\mathrm{kg} / \mathrm{m}^{3}\right)\end{array}$ & 48.5 & 45 & 50 & 56 & 52.5 \\
$\begin{array}{c}\text { 28-day compressive } \\
\text { strength }(\mathrm{MPa})\end{array}$ & 380 & 390 & 520 & 590 & 600 \\
$\begin{array}{c}\text { Drying shrinkage } \\
\text { (microstrain) }\end{array}$ & & & & \\
\hline
\end{tabular}

${ }^{1}$ Replacements of sand with furnace coal bottom-ash (FBA) were performed based on mass (the specific gravity was 2.66 and 1.58 for sand and FBA, respectively).

Table 2. CON-fix-SLUMP-30-60: concrete mixture design with a fixed slump range of 30-60 $\mathrm{mm}$ and the concrete's properties (based on Bai et al. [19]).

\begin{tabular}{cccccc}
\hline Material/property & FBA0 $_{\text {SL30-60 }}$ & FBA30 $_{\text {SL30-60 }}$ & FBA50 $_{\text {SL30-60 }}$ & FBA70 $_{\text {SL30-60 }}$ & FBA100 $_{\text {SL30-60 }}$ \\
\hline $\begin{array}{c}\text { Portland cement } \\
\left(\mathrm{kg} / \mathrm{m}^{3}\right)\end{array}$ & 382 & 382 & 382 & 382 & 382 \\
Water content $\left(\mathrm{kg} / \mathrm{m}^{3}\right)$ & 222 & 191 & 164 & 145 & 122 \\
Sand $\left(\mathrm{kg} / \mathrm{m}^{3}\right)^{1}$ & 604 & 367 & 245 & 137 & 0 \\
FBA $\left(\mathrm{kg} / \mathrm{m}^{3}\right)^{1}$ & 0 & 157 & 245 & 319 & 414 \\
$\begin{array}{c}\text { Coarse aggregate } \\
\left(\mathrm{kg} / \mathrm{m}^{3}\right)\end{array}$ & 1226 & 1284 & 1335 & 1371 & 1414 \\
$\begin{array}{c}\text { 28-day compressive } \\
\text { strength (MPa) } \\
\begin{array}{c}\text { Drying shrinkage } \\
\text { (microstrain) }\end{array}\end{array}$ & 40.8 & 40 & 44.3 & 43.5 & 46.5 \\
\hline
\end{tabular}

${ }^{1}$ Replacements of sand with furnace coal bottom-ash (FBA) were performed based on mass (the specific gravity was 2.66 and 1.58 for sand and FBA, respectively).

Table 3. CON-fix-W/C-0.45: concrete mixture design with a fixed water/cement (W/C) ratio of 0.45 and the concrete's properties (based on Bai et al. [19]).

\begin{tabular}{|c|c|c|c|c|c|}
\hline Material/property & $\mathrm{FBA}_{\mathrm{W} / \mathrm{C} 0.45}$ & FBA $30_{W / C 0.45}$ & FBA $50_{\mathrm{W} / \mathrm{C} 0.45}$ & FBA70 $\mathrm{W} / \mathrm{C} 0.45$ & FBA100 $\mathrm{W} / \mathrm{C} 0.45$ \\
\hline $\begin{array}{l}\text { Portland cement } \\
\qquad\left(\mathrm{kg} / \mathrm{m}^{3}\right)\end{array}$ & 382 & 382 & 382 & 382 & 382 \\
\hline Water content $\left(\mathrm{kg} / \mathrm{m}^{3}\right)$ & 172 & 172 & 172 & 172 & 172 \\
\hline Sand $\left(\mathrm{kg} / \mathrm{m}^{3}\right)^{1}$ & 665 & 374 & 236 & 127 & 0 \\
\hline FBA $\left(\mathrm{kg} / \mathrm{m}^{3}\right)^{1}$ & 0 & 160 & 236 & 296 & 366 \\
\hline $\begin{array}{c}\text { Coarse aggregate } \\
\left(\mathrm{kg} / \mathrm{m}^{3}\right)\end{array}$ & 1329 & 1329 & 1329 & 1329 & 1329 \\
\hline $\begin{array}{l}\text { 28-day compressive } \\
\text { strength }(\mathrm{MPa})\end{array}$ & 54 & 59.3 & 56.5 & 52 & 46 \\
\hline $\begin{array}{l}\text { Drying shrinkage } \\
\text { (microstrain) }\end{array}$ & 560 & 400 & 400 & 380 & 320 \\
\hline
\end{tabular}

${ }^{1}$ Replacements of sand with furnace coal bottom-ash (FBA) were performed based on mass (the specific gravity was 2.66 and 1.58 for sand and FBA, respectively). 
Table 4. CON-fix-W/C-0.55: concrete mixture design with a fixed water/cement (W/C) ratio of 0.55 and the concrete's properties (based on Bai et al. [19]).

\begin{tabular}{cccccc}
\hline Material/property & FBA0 $_{W / C 0.55}$ & FBA30 $_{W / C 0.55}$ & FBA50 $_{W / C 0.55}$ & FBA70 $_{W / C 0.55}$ & FBA100 $_{W / C 0.55}$ \\
\hline $\begin{array}{c}\text { Portland cement } \\
\left(\mathrm{kg} / \mathrm{m}^{3}\right)\end{array}$ & 382 & 382 & 382 & 382 & 382 \\
\hline Water content $\left(\mathrm{kg} / \mathrm{m}^{3}\right)$ & 210 & 210 & 210 & 210 & 210 \\
\hline Sand $\left(\mathrm{kg} / \mathrm{m}^{3}\right)^{1}$ & 628 & 353 & 223 & 120 & 0 \\
\hline FBA $\left(\mathrm{kg} / \mathrm{m}^{3}\right)^{1}$ & 0 & 151 & 223 & 280 & 346 \\
\hline $\begin{array}{c}\text { Coarse aggregate } \\
\left(\mathrm{kg} / \mathrm{m}^{3}\right)\end{array}$ & 1256 & 1256 & 1256 & 1256 & 286 \\
\hline $\begin{array}{c}\text { 28-day compressive } \\
\text { strength }(\mathrm{MPa})\end{array}$ & 48.3 & 46 & 40 & 36 & 370 \\
\hline $\begin{array}{c}\text { Drying shrinkage } \\
\text { (microstrain) }\end{array}$ & 550 & 480 & 380 & 360 & 286 \\
\hline
\end{tabular}

${ }^{1}$ Replacements of sand with furnace coal bottom-ash (FBA) were performed based on mass (the specific gravity was 2.66 and 1.58 for sand and FBA, respectively).

Table 5. Particle size distribution of the sand and furnace coal bottom-ash (FBA) (based on Bai et al. [19]).

\begin{tabular}{cccccccccccccccc}
\hline \multirow{10}{*}{ Material Size of test sieve (mm) } \\
\cline { 2 - 6 } & 0.075 & 0.15 & 0.212 & 0.3 & 0.425 & 0.6 & 0.85 & 1.18 & 1.7 & 2.36 & 3.35 & 5 & 6.3 & 10 \\
\hline \multicolumn{10}{c}{ Cumulative percentage passing (\%) } \\
\hline Sand & 2 & 8 & 15 & 25 & 41 & 58 & 72 & 82 & 94 & 100 & 100 & 100 & 100 & 100 \\
\hline FBA & 8 & 41 & 50 & 55 & 60 & 62 & 68 & 73 & 80 & 88 & 90 & 95 & 98 & 100 \\
\hline
\end{tabular}

Table 6. Chemical composition of furnace coal bottom-ash (FBA) (wt\%) (based on Bai et al. [19]).

\begin{tabular}{cccccccccccc}
\hline $\mathrm{SiO}_{2}$ & $\mathrm{Al}_{2} \mathrm{O}_{3}$ & $\mathrm{Fe}_{2} \mathrm{O}_{3}$ & $\mathrm{MgO}$ & $\mathrm{CaO}$ & $\mathrm{Na}_{2} \mathrm{O}$ & $\mathrm{K}_{2} \mathrm{O}$ & $\mathrm{TiO}_{2}$ & $\mathrm{SO}_{3}$ & $\mathbf{P}_{2} \mathrm{O}_{5}$ & Others & LOI \\
\hline 61.8 & 17.80 & 6.97 & 1.34 & 3.19 & 0.95 & 2.00 & 0.88 & 0.79 & 0.2 & 0.49 & 3.61 \\
\hline
\end{tabular}

\subsection{Life-Cycle Assessment}

In this study, LCAs were conducted by defining the FU and system boundaries, analyzing the performance of the life-cycle inventory (LCI), and evaluating the life-cycle impact assessment (LCIA) [15]. According to [20], an LCA of concrete should include (i) the design stage, (ii) the production/execution stage, (iii) the usage stage, and (iv) the end-of-life stage. However, for structural concretes, the usage stage is different for different building elements, such as beams, pillars, and walls [21]. For example, foundational and load-bearing elements (beams and pillars) can serve from 50 to 300 years, whereas exterior surfaces (walls) can serve from 20 to 50 years [22]. Therefore, the usage stage is usually excluded from LCAs of concretes [23]. Additionally, the end-of-life stage of structural concretes is highly dependent on the applied demolition and disposal practices and is thus highly uncertain [24]. Therefore, in this study, only a "cradle-to-gate" LCA, which evaluated the production of the CON-fix-SLUMP-0-10, CON-fix-SLUMP-30-60, CON-fix-W/C-0.45, and CON-fix-W/C-0.55 concretes, was conducted.

\subsubsection{Functional Unit (FU), System Boundary, and Life-Cycle Inventory (LCI)}

The FU, to which the inputs and outputs must be connected [15], was $1 \mathrm{~m}^{3}$ of a concrete mixture. The environmental assessment of this FU was normalized to the 28-day concrete compressive strength, as suggested by [18]. 
The system boundaries of the LCAs included concrete component production with the relevant raw materials and the transport of the concrete components to the concrete batching plant. The SimaPro v9.0 software platform [25], together with data from the Ecoinvent v3.2 database (Tables 7 and 8), was used to model the LCI of the production stage of the concrete components (cement, aggregates, and water). These data were used due to the absence of local Israeli data. However, such an analysis of secondary data was acceptable given the aim of the study, i.e., to compare different methods of byproduct-based concrete design.

Table 7. References from the EcoInvent v3.2 database [25] used for modeling the life cycle of the CON-fix-SLUMP-0-10, CON-fix-SLUMP-30-60, CON-fix-W/C-0.45, and CON-fix-W/C-0.55 concretes.

\begin{tabular}{cc}
\hline Process & Reference \\
\hline Water treatment & Tap water, at user/CH U \\
Cement production & Cement mortar, at plant/CH U \\
Coarse aggregate extraction & Gravel, crushed, at mine, CH/ U \\
Sand extraction & Sand, at mine CH/ U \\
Transport & Lorry transport, Euro $0,1,2,3,4$ mix, $22 \mathrm{t}$ total weight, $17.3 \mathrm{t}$ \\
\hline
\end{tabular}

Table 8. Life-cycle inventory for the evaluation of the CON-fix-SLUMP-0-10, CON-fix-SLUMP-30-60, CON-fix-W/C-0.45, and CON-fix-W/C-0.55 concretes (EcoInvent v3.2 database [25]).

\begin{tabular}{ccccc}
\hline Process & $\begin{array}{c}\text { GWP } \\
(\mathbf{k g ~ C O} \mathbf{~}\end{array}$ & $\begin{array}{c}\text { TE } \\
(\mathbf{k g ~ 1 , 4 - D C B})\end{array}$ & $\begin{array}{c}\text { FRS } \\
\mathbf{( k g ~ o i l ~} \mathbf{~ e q})\end{array}$ & $\begin{array}{c}\text { WC } \\
\mathbf{( m}^{\mathbf{3}} \mathbf{)}\end{array}$ \\
\hline Water treatment $(1 \mathrm{~kg})$ & 0.000171 & 0.000409 & - & 0.00448 \\
Cement production $(1 \mathrm{~kg})$ & 0.192 & 0.251 & - & 0.565 \\
Coarse aggregate & 0.00445 & 0.0167 & - & 0.081 \\
extraction $(1 \mathrm{~kg})$ & 0.00242 & 0.0067 & - & 0.026 \\
Sand extraction $(1 \mathrm{~kg})$ & 0.0663 & 0.00589 & 0.0201 & 0.00000529 \\
Transport $(1 \mathrm{~km})$ &
\end{tabular}

GWP: global warming potential; TE: Terrestrial Ecotoxicity; FRS: Fossil Resource Scarcity; WC: Water Consumption.

The production of cement included the provision of raw materials, mixing, packing, and storage. The water treatment included the energy required for water treatment. The extraction of gravel and sand involved the digging of the gravel and sand (Ecoinvent v3.2). The local transportation distances for the concrete components to the batching plant were modeled in SimaPro. Coarse aggregates and sand were transported from a natural aggregate quarry to a concrete plant located at a distance of 50 $\mathrm{km}$ from the quarry, while cement and FBA were transported from a cement plant and a coal-fired power plant, respectively, to a concrete plant located at a distance of $100 \mathrm{~km}$ from both plants.

For the FBA processing, only the transportation of the FBA from coal-fired power plants to concrete plants was evaluated. This means that the FBA was considered as waste. This is due to the uncertainties involved in the attributional and consequential modeling of byproducts [14].

\subsubsection{The ReCiPe2016 Life-Cycle Impact Assessment (LCIA) Method}

The ReCiPe2016 LCIA method was applied in this study. ReCiPe2016 includes three perspectives from cultural theory [26]: individualist (I), which evaluates all of the short-term damaging effects; egalitarian (E), which evaluates all of the possible long-term damaging effects; and hierarchist $(\mathrm{H})$, which evaluates the balance between the short- and long-term damaging effects [27]. These three perspectives can be evaluated using the ReCiPe2016 midpoint and single-score methods [25]. The ReCiPe2016 single-score method uses average and particular weighting sets. The average weighting set includes the individualist/average (I/A), hierarchist/average (H/A), and egalitarian/average (E/A) methodological options, and the particular weighting set includes the individualist/individualist (I/I), hierarchist/hierarchist $(\mathrm{H} / \mathrm{H})$, and egalitarian/egalitarian (E/E) methodological options. 
The use of each of the two ReCiPe2016 methods has inherent advantages and disadvantages. The midpoint method has a lower uncertainty in environmental evaluations, and the interpretation of its results is more complex. Meanwhile, the single-score method has a higher uncertainty in environmental evaluations, but the interpretation of its results is less complex [27].

Therefore, the environmental impacts of the CON-fix-SLUMP-0-10, CON-fix-SLUMP-30-60, CON-fix-W/C-0.45, and CON-fix-W/C-0.55 concretes were evaluated using both of the ReCiPe2016 methods. The midpoint $\mathrm{H}$ method was used to evaluate only the four most significant environmental impacts: GWP, terrestrial ecotoxicity, fossil resource scarcity, and water consumption. The single-score method was used to evaluate the following six methodological options: I/A, H/A, E/A, I/I, H/H, and E/E. A two-stage nested (hierarchical) analysis of variance (ANOVA) was used to simultaneously evaluate the results of the six ReCiPe2016 methodological options [28].

\subsection{Statistical Evaluation}

Statistical evaluations were performed in a two-step procedure: (i) a two-stage ANOVA model structure that was appropriate for the six methodological options of the ReCiPe2016 model was constructed; and (ii) the ReCiPe2016 LCA results for the CON-fix-SLUMP-0-10, CON-fix-SLUMP-30-60, CON-fix-W/C-0.45, and CON-fix-W/C-0.55 alternative concretes were statistically analyzed.

\subsubsection{Determining the Appropriate ANOVA Design Structure}

We used an ANOVA design structure based on the following statistical terminology: sampling frame, primary sampling unit, subunits, and individual subunits, which were initially recommended by [29]. The sampling frame was defined as the collection of all elements (primary sampling units) that were accessible for sampling in the population of interest. The primary sampling unit is an element within the sampling frame that is sampled and statistically independent of the other sampling units within the frame. As a result, a two-stage nested ANOVA model includes a primary unit within which subunits are nested and a subunit within which individual subunits are nested. Measurements were collected from the individual subunits.

Figure 1 shows two primary sampling units, i.e., the ReCiPe2016 result of an FBA0 $0_{\text {SL0-10 }}$

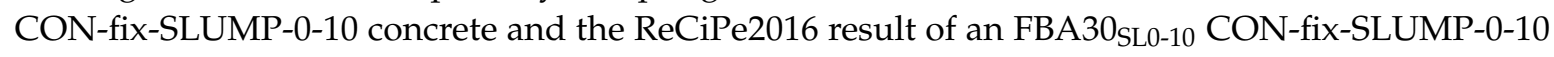
concrete. The primary sampling unit included two subunits, i.e., the particular and average weighting sets, and each subunit included three individual subunits, giving a total of six methodological options. Measurements were collected from the individual subunits. Therefore, five concretes with $0,30,50$, 70 , and $100 \mathrm{wt} \%$ of sand replaced with FBA were compared in pairs for the CON-fix-SLUMP-0-10, CON-fix-SLUMP-30-60, CON-fix-W/C-0.45, and CON-fix-W/C-0.55 concretes. 

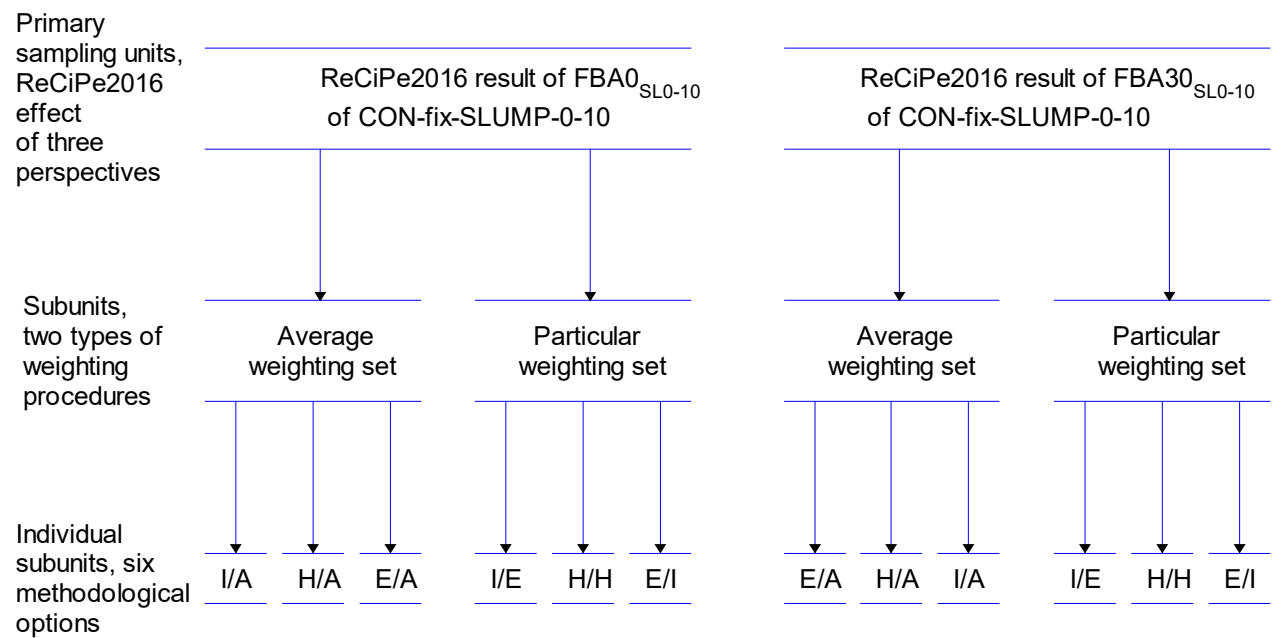

Figure 1. Structure of the two-stage nested hierarchical analysis of variance (ANOVA) that was used for the environmental evaluation of the concretes with a fixed slump range of $0-10 \mathrm{~mm}$ (CON-fix-SLUMP-0-10), i.e., FBA0 ${ }_{S L 0-10}$ and FBA30 ${ }_{\text {SL0-10. The following are the methodological }}$ options of the ReCiPe2016 single-score results: I/A: individualist/average; H/A: hierarchist/average; E/A: egalitarian/average; I/I: individualist/individualist; $\mathrm{H} / \mathrm{H}$ : hierarchist/hierarchist; and $\mathrm{E} / \mathrm{E}$ : egalitarian/egalitarian.

\subsubsection{Statistical Analysis}

First, the ReCiPe2016 results were multiplied by $10^{3}$ and were log10-transformed. The differences between the two ReCiPe2016 results were then analyzed using a two-stage ANOVA [28]. The P-values were evaluated according to the three-valued logic: "appears to be positive," "appears to be negative," and "judgment is suspended" [30]. In this study, the logic values were, "there appears to be a difference between the CON-fix-SLUMP-0-10, CON-fix-SLUMP-30-60, CON-fix-W/C-0.45, or CON-fix-W/C-0.55 concretes," "there does not appear to be a difference between the CON-fix-SLUMP-0-10, CON-fix-SLUMP-30-60, CON-fix-W/C-0.45, or CON-fix-W/C-0.55 concretes," and "judgment was suspended with respect to the difference between the CON-fix-SLUMP-0-10, CON-fix-SLUMP-30-60, CON-fix-W/C-0.45, or CON-fix-W/C-0.55 concretes".

\section{Results}

\subsection{CON-fix-SLUMP-0-10 and CON-fix-SLUMP-30-60}

\subsubsection{The ReCiPe2016 Midpoint}

The CON-fix-SLUMP-0-10 concretes (Figure 2) and CON-fix-SLUMP-30-60 concretes (Figure 3) exhibited similar tendencies in the impacts of GWP, terrestrial ecotoxicity, fossil resource scarcity, and water consumption. As shown in Figures 2 and 3, the impacts of GWP, terrestrial ecotoxicity, and water consumption were lower in the byproduct-based concretes (FBA50 SL0-10, FBA70 $_{\text {SL0-10, FBA100 }}$ SL0-10,

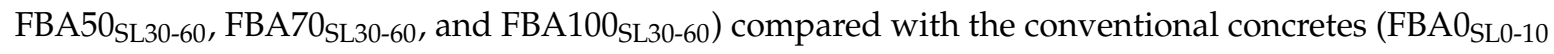
and $\left.\mathrm{FBA} 0_{\mathrm{SL} 30-60}\right)$. These results indicate that when the sand in the concrete was sequentially replaced with FBA, the resulting decrease in the quantity of sand and water was greater than the increase in the traffic load due to the transportation of FBA from the coal-fired power plant to the local concrete batching plant and the increase in the quantity of coarse aggregates. The only exceptions to this

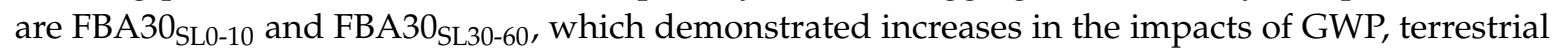
ecotoxicity, and water consumption compared to FBA0 (Figures 2 and 3, respectively). 

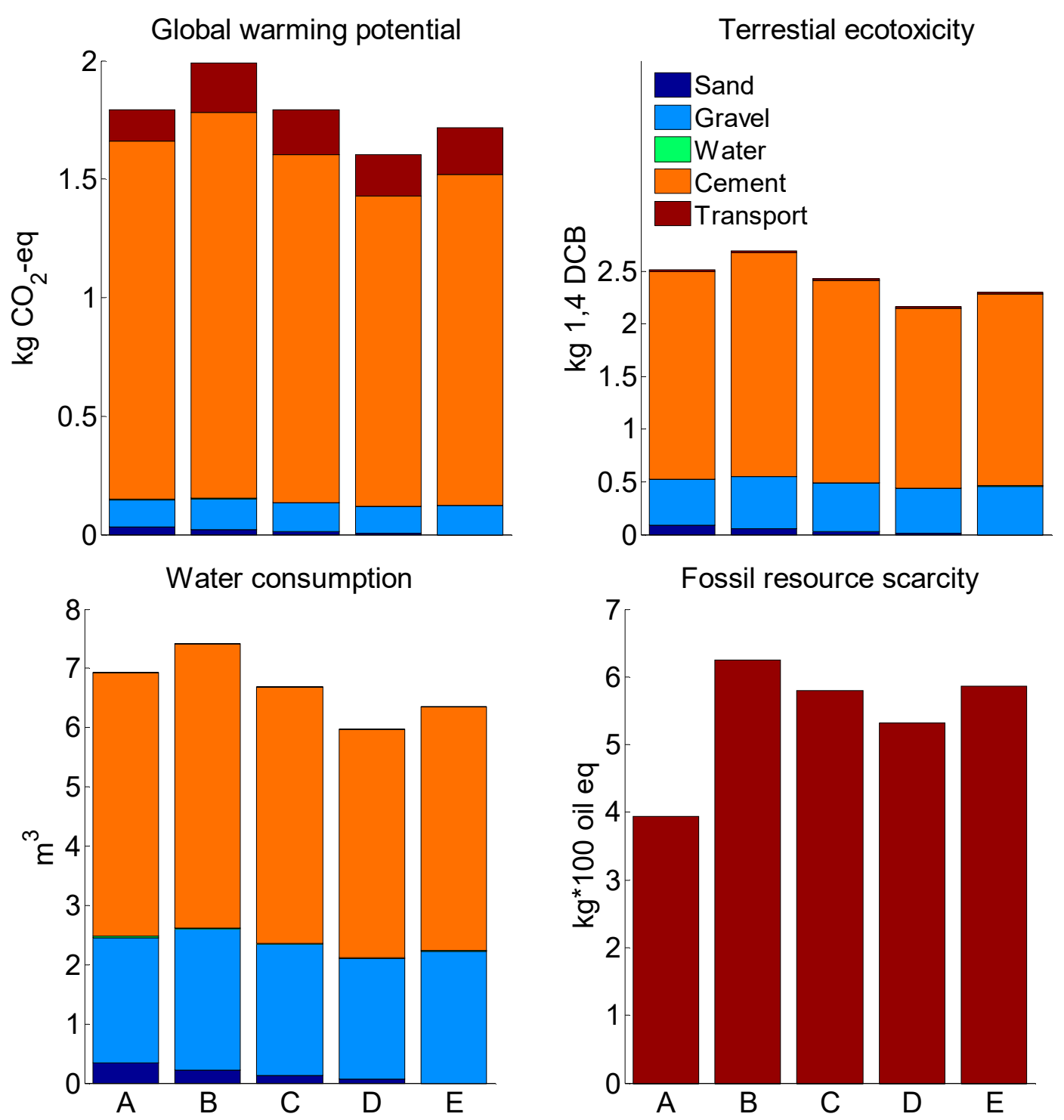

Figure 2. The environmental impacts of replacing sand with furnace coal bottom-ash (FBA) in

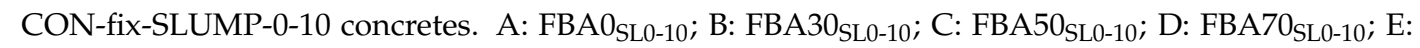
FBA100 5 0-10. The functional unit $(\mathrm{FU})$ was $1 \mathrm{~m}^{3}$ of concrete normalized to the 28-day concrete compressive strength. The ReCiPe2016 midpoint hierarchist method was used.

In contrast, the impact of the fossil resource scarcity of the byproduct-based concretes (FBA30 SL0-10, $_{\text {, }}$

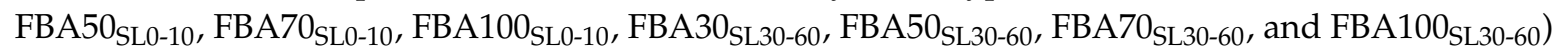
was higher than that of conventional concretes (FBA0 SL0-10 $_{\text {and FBA0 }}$ SL30-60 (Figures 2 and 3). The transportation load of FBA is one factor which contributes to this impact. 

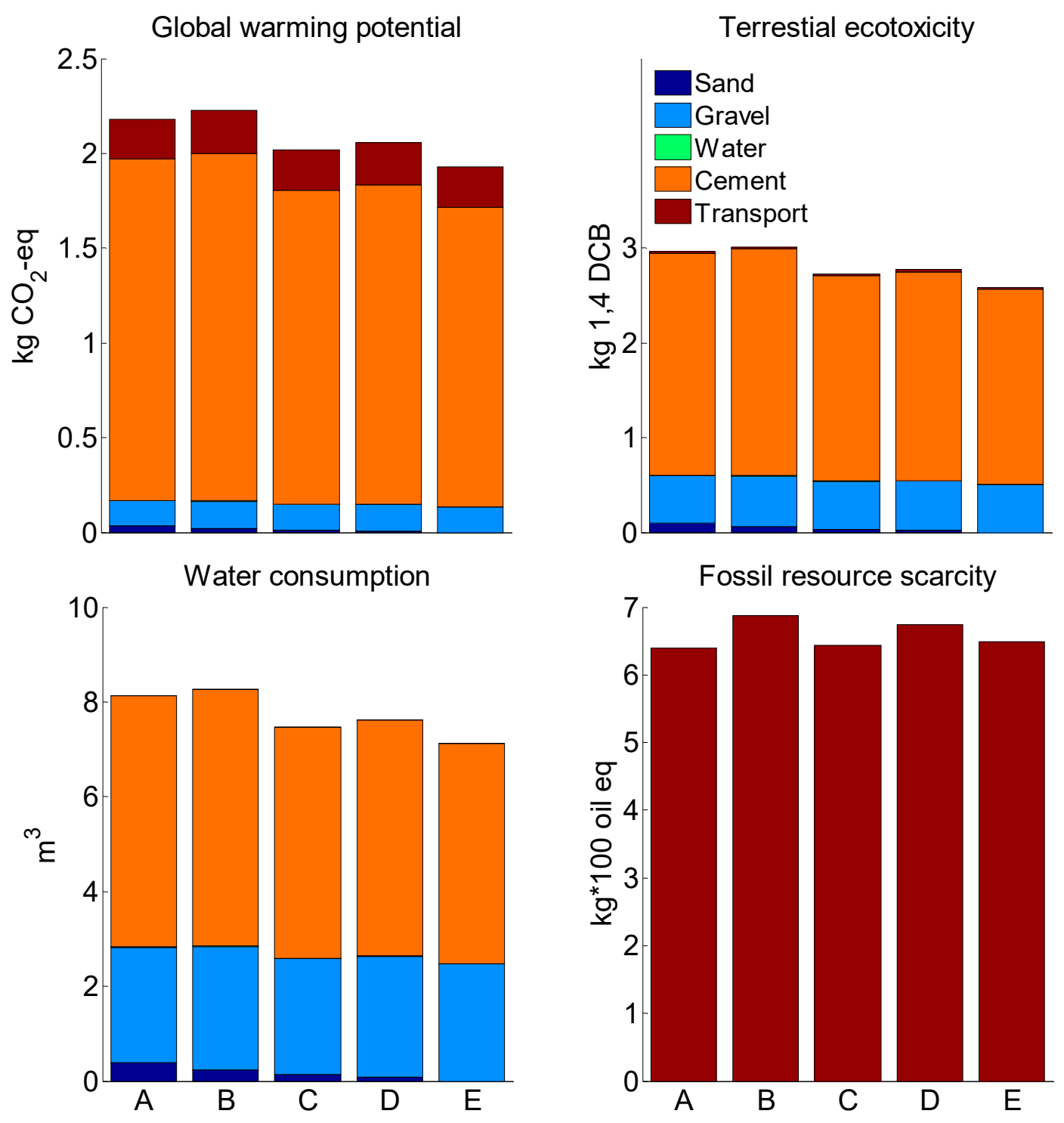

Figure 3. The environmental impacts of replacing sand with furnace coal bottom-ash (FBA) in concretes with a fixed slump range of 30-60 mm (CON-fix-SLUMP-30-60). A: FBA0 SL0-10; $_{\text {B }}$ FBA30 SL0-10; $_{\text {C: }}$ FBA50 $_{\text {SL0-10 }}$; D: FBA70 SL0-10 $_{\text {E: FBA100 }}$ SL0-10. The functional unit $(\mathrm{FU})$ was $1 \mathrm{~m}^{3}$ of concrete normalized to the 28-day concrete compressive strength. The ReCiPe2016 midpoint hierarchist method was used.

\subsubsection{The Six Methodological Options of the ReCiPe2016 Single-Score Method}

The environmental impacts of the CON-fix-SLUMP-0-10 and CON-fix-SLUMP-30-60 concretes

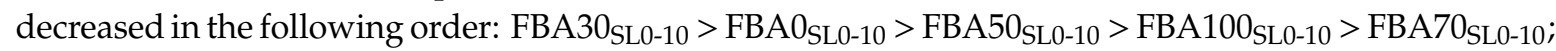
and FBA30 $_{\text {SL30-60 }}>$ FBA0 $_{\text {SL30-60 }}>$ FBA50 $_{\text {SL30-60 }}>$ FBA100 $_{\text {SL30-60 }}>$ FBA70 $_{\text {SL30-60 }}$ (Figures 4 and 5, respectively). The same order of increase was observed for all of the six ReCiPe2016 single-score methodological options. 


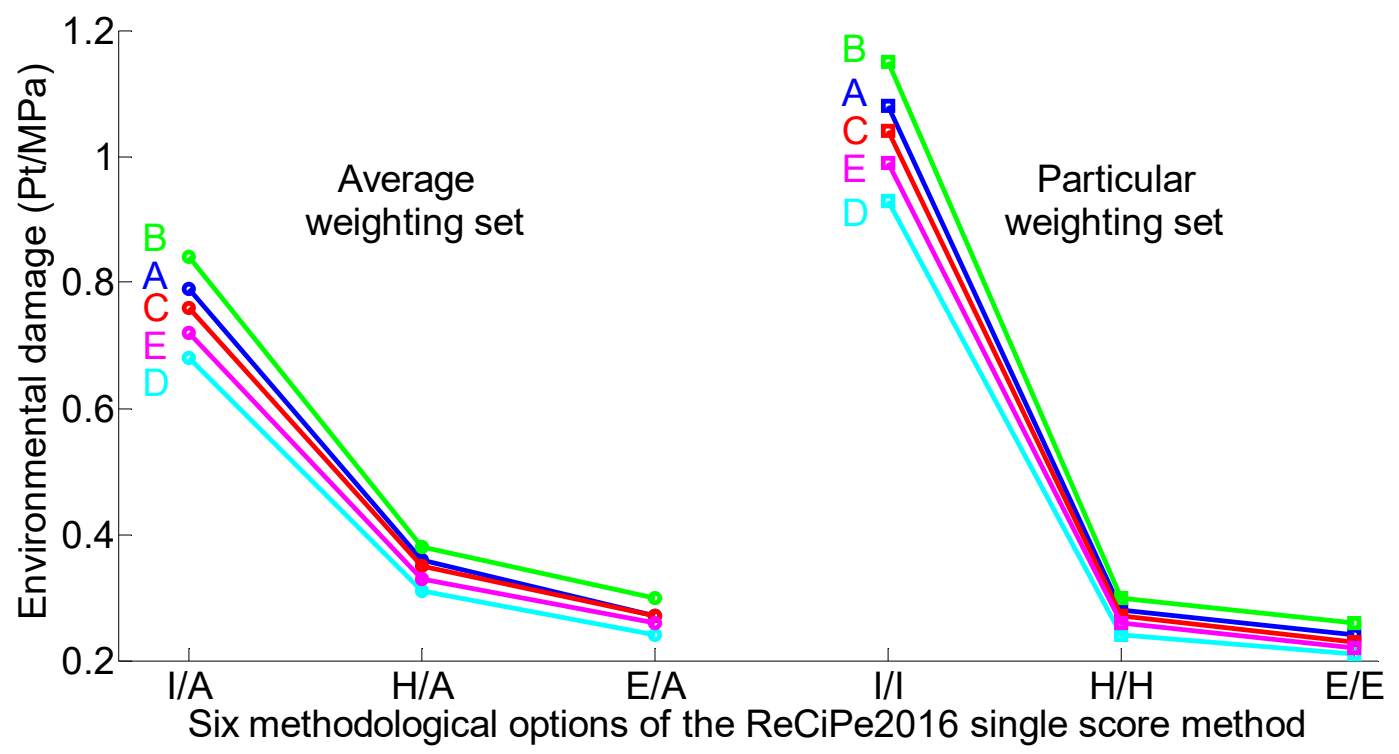

Figure 4. The environmental impacts of replacing sand with furnace coal bottom-ash (FBA) in

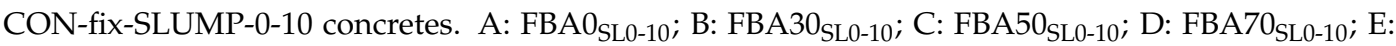
FBA100 5 L-10. The functional unit (FU) was $1 \mathrm{~m}^{3}$ of concrete normalized to the 28-day concrete compressive strength. The life-cycle assessments (LCAs) (production stage) were evaluated via the six methodological options of the ReCiPe2016 single-score method.

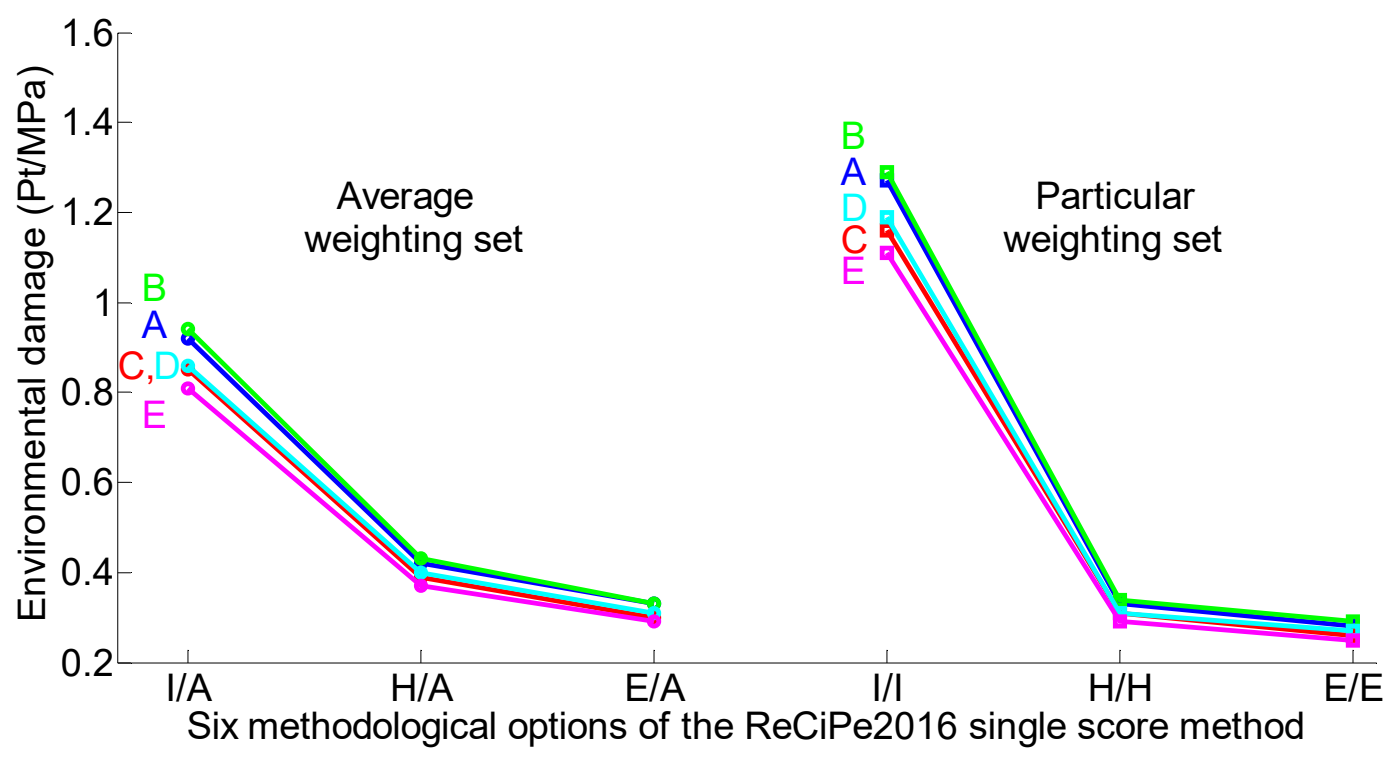

Figure 5. The environmental impacts of replacing sand with furnace coal bottom-ash (FBA) in

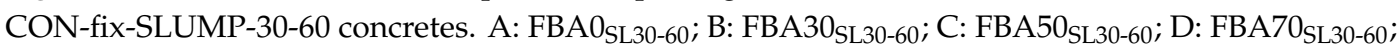

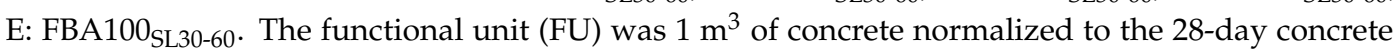
compressive strength. The life-cycle assessments (LCAs) (production stage) were evaluated via the six methodological options of the ReCiPe2016 single-score method.

The analysis of the CON-fix-SLUMP-0-10 concretes (Table 9) showed that the differences between

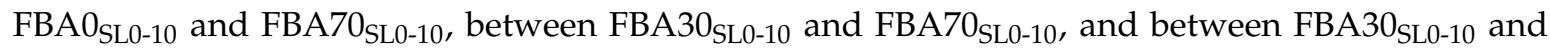
FBA1000 $\mathrm{SL0-10}$, were positive to a statistically significant degree $(0.0060 \leq \mathrm{P} \leq 0.0144)$. Meanwhile,

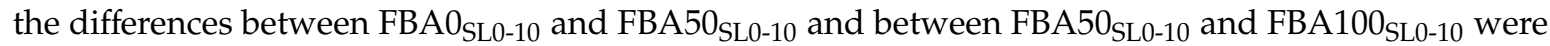
found to be negative to a statistically significant degree ( $P=0.2664$ and $P=0.1762$, respectively). Judgment was suspended for the differences between all remaining pairs $(0.0360 \leq \mathrm{P} \leq 0.0784)$. 
Table 9. P-values of the differences in single-score evaluation between pairs of CON-fix-SLUMP-0-10 concretes for the life-cycle assessment (LCA) (production stage) of $1 \mathrm{~m}^{3}$ of concrete normalized to the 28-day concrete compressive strength. The LCAs were evaluated via the six ReCiPe2016 single-score methodological options.

\begin{tabular}{cccccc}
\hline Concrete & FBA0 $_{\text {SL0-10 }}$ & FBA30 $_{\text {SL0-10 }}$ & FBA50 $_{\text {SL0-10 }}$ & FBA70 $_{\text {SL0-10 }}$ & FBA100 $_{\text {SL0-10 }}$ \\
\hline FBA0 $_{\text {SL0-10 }}$ & $\mathrm{X}$ & 0.0376 & 0.2664 & $\mathbf{0 . 0 1 2 1}$ & 0.0462 \\
FBA30 $_{\text {SL0-10 }}$ & & $\mathrm{X}$ & 0.0386 & $\mathbf{0 . 0 0 6 0}$ & $\mathbf{0 . 0 1 4 4}$ \\
FBA50 $_{\text {SL0-10 }}$ & & & $\mathrm{X}$ & 0.0360 & 0.1762 \\
FBA70 $_{\text {SL0-10 }}$ & & & & $\mathrm{X}$ & 0.0784 \\
FBA100 $_{\text {SL0-10 }}$ & & & & & $\mathrm{X}$ \\
\hline
\end{tabular}

Notes: Bold font: a positive difference was found between the compared concretes; Ordinal font: a negative difference was found between the compared concretes; Italic font: judgment was suspended regarding the difference between the compared concretes.

The analysis of the CON-fix-SLUMP-30-60 concretes (Table 10) showed that the differences

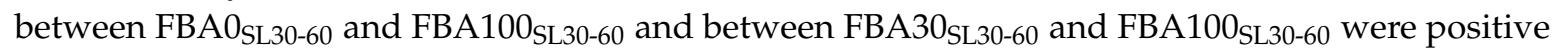
to a statistically significant degree $(P=0.0115$ and $P=0.0103$, respectively). Meanwhile, the

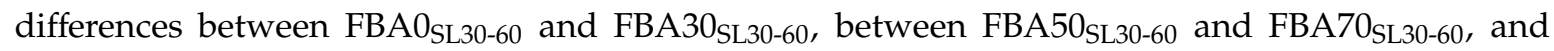
between FBA50 $0_{\mathrm{SL} 30-60}$ and FBA100 $\mathrm{SL30-60}$ were found to be negative to a statistically significant degree $(0.1020 \leq \mathrm{P} \leq 0.3198)$. Judgment was suspended for the differences between all remaining pairs $(0.0301 \leq \mathrm{P} \leq 0.0620)$.

Table 10. P-values of the differences in single-score evaluation between pairs of CON-fix-SLUMP-30-60 concretes for the life-cycle assessment (LCA) (production stage) of $1 \mathrm{~m}^{3}$ of concrete normalized to the 28-day concrete compressive strength. The LCAs were evaluated via the six ReCiPe2016 single-score methodological options.

\begin{tabular}{cccccc}
\hline Concrete & FBA0 $_{\text {SL30-60 }}$ & FBA30 $_{\text {SL30-60 }}$ & FBA50 $_{\text {SL30-60 }}$ & FBA70 $_{\text {SL30-60 }}$ & FBA100 $_{\text {SL30-60 }}$ \\
\hline FBA0 $_{\text {SL30-60 }}$ & $\mathrm{X}$ & 0.3198 & 0.0442 & 0.0859 & $\mathbf{0 . 0 1 1 5}$ \\
FBA30 $_{\text {SL30-60 }}$ & & $\mathrm{X}$ & 0.0620 & 0.0301 & $\mathbf{0 . 0 1 0 3}$ \\
FBA50 $_{\text {SL30-60 }}$ & & & $\mathrm{X}$ & 0.2851 & 0.1020 \\
FBA70 $_{\text {SL30-60 }}$ & & & & $\mathrm{X}$ & 0.0556 \\
FBA100 $_{\text {SL30-60 }}$ & & & & $X$ \\
\hline
\end{tabular}

Notes: Bold font: a positive difference was found between the compared concretes; Ordinal font: a negative difference was found between the compared concretes; Italic font: judgment was suspended regarding the difference between the compared concretes.

Therefore, according to the rankings (Figures 4 and 5) and P-value analyses (Tables 9 and 10) of the LCA results, the CON-fix-SLUMP-0-10 concretes with the lowest environmental impact were found to be

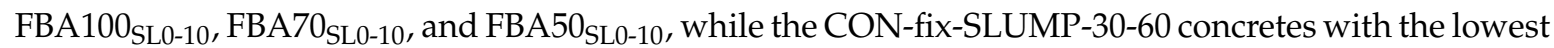

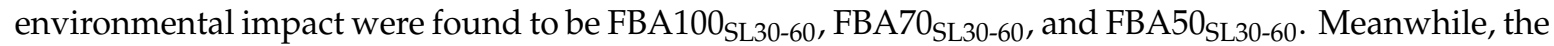
CON-fix-SLUMP-0-10 concretes with the highest environmental impact were found to be FBA30 and FBA0 $0_{\text {SL0-10, }}$, while the CON-fix-SLUMP-30-60 concretes with the highest environmental impact were found to be FBA30 $0_{\text {SL30-60 }}$ and FBA0 $0_{\text {SL30-60 }}$.

\subsection{CON-fix-W/C-0.45 and CON-fix-W/C-0.55}

\subsubsection{The ReCiPe2016 Midpoint}

Figure 6 illustrates four environmental impacts of the CON-fix-W/C- 0.45 concretes. The increasing replacement of sand by FBA in the concretes (i.e., progressing from FBA30 $0_{\mathrm{W} / \mathrm{C} 0.45}$ to $\mathrm{FBA} 50_{\mathrm{W} / \mathrm{C} 0.45}$ to $\mathrm{FBA} 70_{\mathrm{W} / \mathrm{C} 0.45}$ to $\mathrm{FBA} 100_{\mathrm{W} / \mathrm{C} 0.45}$ ) led to gradual increases in all four environmental impacts (GWP, terrestrial ecotoxicity, water consumption, and fossil resource scarcity), while the magnitudes of the environmental impacts of $\mathrm{FBA}_{\mathrm{W} / \mathrm{C} 0.45}$ were between those of $\mathrm{FBA} 50_{\mathrm{W} / \mathrm{C} 0.45}$ and $\mathrm{FBA} 70_{\mathrm{W} / \mathrm{C} 0.45}$. 

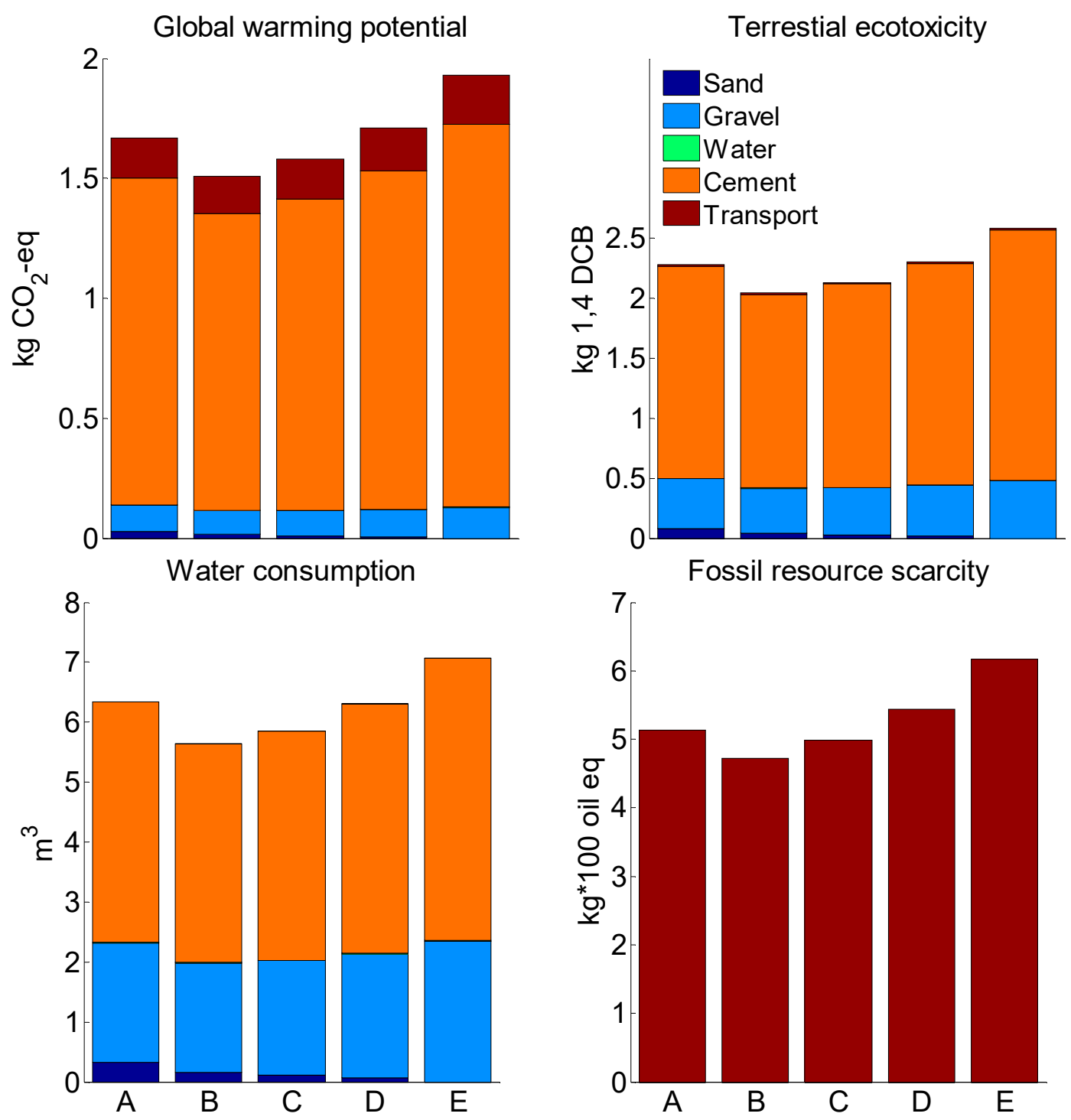

Figure 6. The environmental impacts of replacing sand with furnace coal bottom-ash (FBA) in concretes with a fixed water/cement $(\mathrm{W} / \mathrm{C})$ ratio of $0.45\left(\mathrm{CON}\right.$-fix-W/C-0.45). A: FBA0 $\mathrm{W} / \mathrm{C} 0.45 ; \mathrm{B}: \mathrm{FBA} 30_{\mathrm{W} / \mathrm{C} 0.45}$; C: $\mathrm{FBA} 50_{\mathrm{W} / \mathrm{C} 0.45}$; D: FBA70W/C0.45; E: FBA100W/C0.45. The functional unit (FU) was $1 \mathrm{~m}^{3}$ of concrete normalized to the 28-day concrete compressive strength. The ReCiPe2016 midpoint hierarchist method was used.

Figure 7 depicts the environmental impacts of the CON-fix-W/C-0.55 concrete. As shown in the figure, the increasing replacement of sand with $\mathrm{FBA}$ (i.e., progressing from $\mathrm{FBA} 0_{\mathrm{W} / \mathrm{C} 0.55}$ to FBA100 $/$ /C0.55) led to gradual increases in all four environmental impacts. 

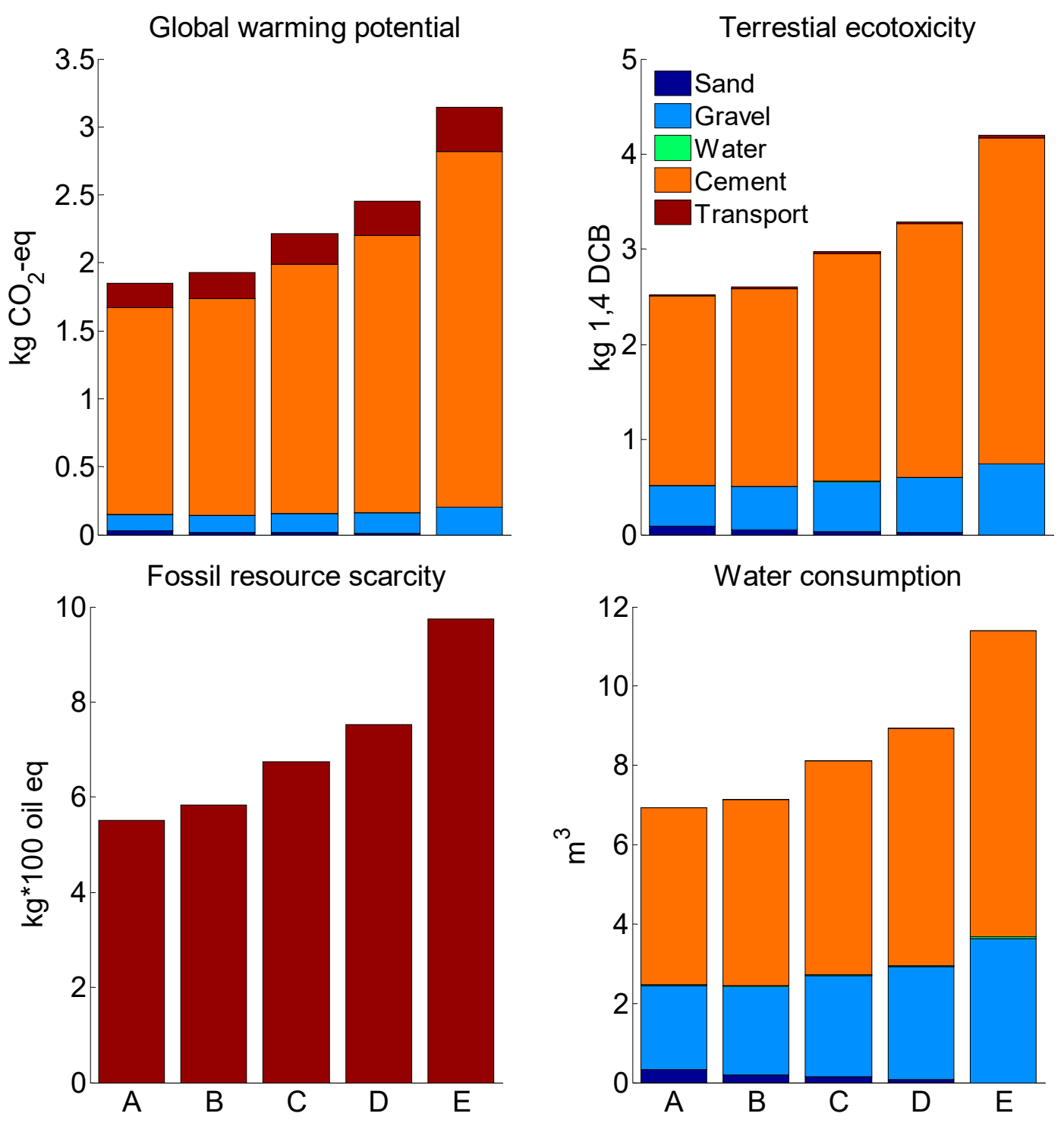

Figure 7. The environmental impacts of replacing sand with furnace coal bottom-ash (FBA) in concretes

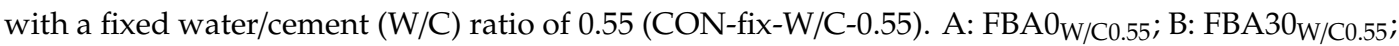
C: FBA50W/C0.55; D: FBA70W/C0.55; E: FBA100W/C0.55. The functional unit (FU) was $1 \mathrm{~m}^{3}$ of concrete normalized to the 28-day concrete compressive strength. The ReCiPe2016 midpoint hierarchist method was used.

According to the analysis of GWP, terrestrial ecotoxicity, water consumption, and fossil resource scarcity, there were two multidirectional factors responsible for the variation in these four parameters: sand production and transport (i.e., the transport of CBA from the coal-fired power plant to the cement plant). The magnitudes of these two factors were similar. However, the 28-day concrete compressive strength was significantly lower in concretes FBA100 ${ }_{\mathrm{W} / \mathrm{C} 0.45}$ (Table 3), $\mathrm{FBA} 70_{\mathrm{W} / \mathrm{C} 0.55}$, and FBA100 $0_{\mathrm{W} / \mathrm{C} 0.55}$ (Table 4). This decrease in the 28-day compressive strength was a responsible factor for the increase in all four environmental impacts when the FU was normalized to the 28-day compressive strength.

\subsubsection{The Six Methodological Options for the ReCiPe2016 Single-Score Method}

As shown in Figure 8, the environmental impacts of the CON-fix-W/C-0.45 concretes decreased in

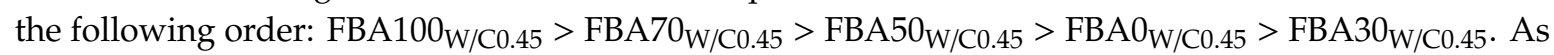
shown in Figure 9, the environmental impacts of the CON-fix-W/C-0.55 concretes decreased in the 
following order: $\mathrm{FBA} 100_{\mathrm{W} / \mathrm{C} 0.55}>\mathrm{FBA} 0_{\mathrm{W} / \mathrm{C} 0.55}>\mathrm{FBA} 0_{\mathrm{W} / \mathrm{C} 0.55}>\mathrm{FBA}_{3} 0_{\mathrm{W} / \mathrm{C} 0.55}>\mathrm{FBA0} 0_{\mathrm{W} / \mathrm{C} 0.55}$. This order was exhibited for all six methodological options for the ReCiPe2016 single-score results.

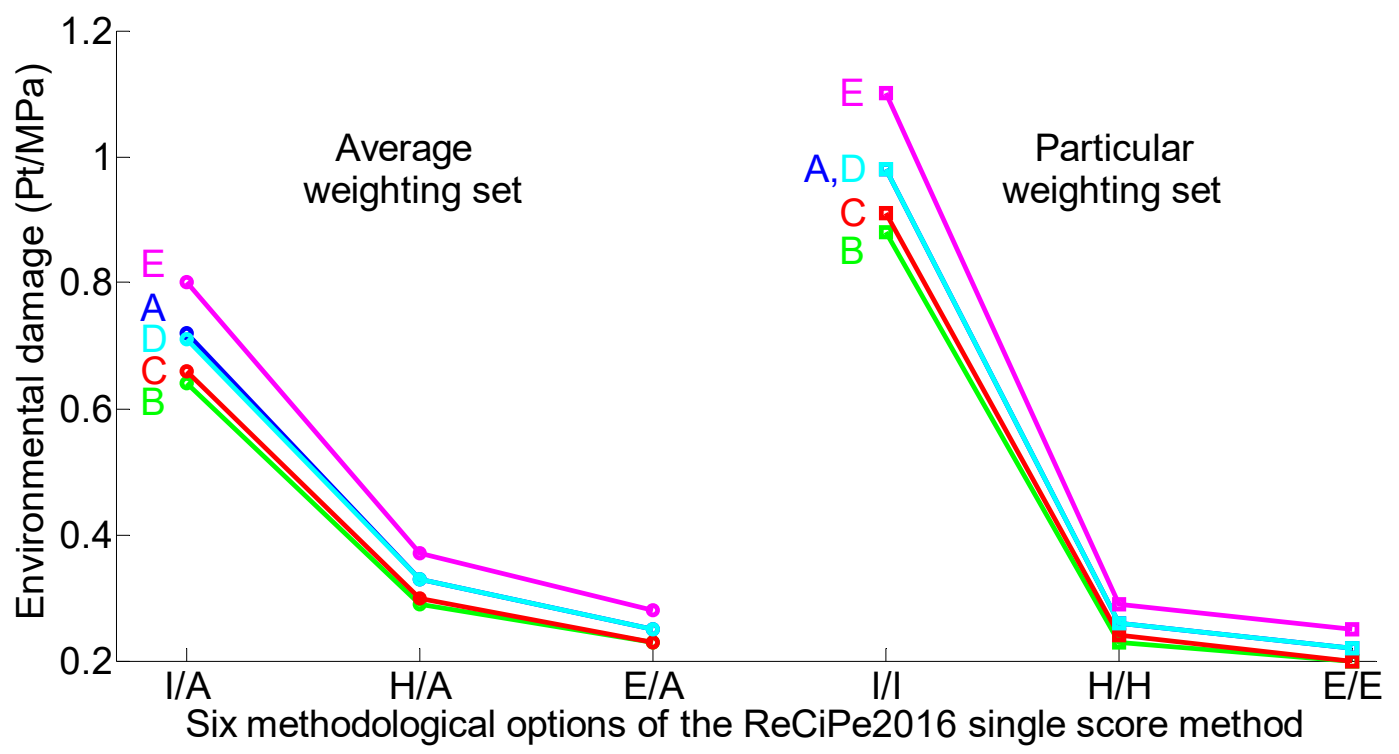

Figure 8. The environmental impacts of replacing sand with furnace coal bottom-ash (FBA) in CON-fix-W/C-0.45 concretes. A: FBA0 $0_{\mathrm{W} / \mathrm{C} 0.45}$; B: FBA30 $3 / \mathrm{C} 0.45 ; \mathrm{C}: \mathrm{FBA} 50_{\mathrm{W} / \mathrm{C} 0.45}$; D: FBA70 $\mathrm{W} / \mathrm{C} 0.45 ; \mathrm{E}$ : FBA100 $\mathrm{W} / \mathrm{C} 0.45$. The functional unit (FU) was $1 \mathrm{~m}^{3}$ of concrete normalized to the 28-day concrete compressive strength. The life-cycle assessments (LCAs) (production stage) were evaluated via the six methodological options of the ReCiPe2016 single-score method.

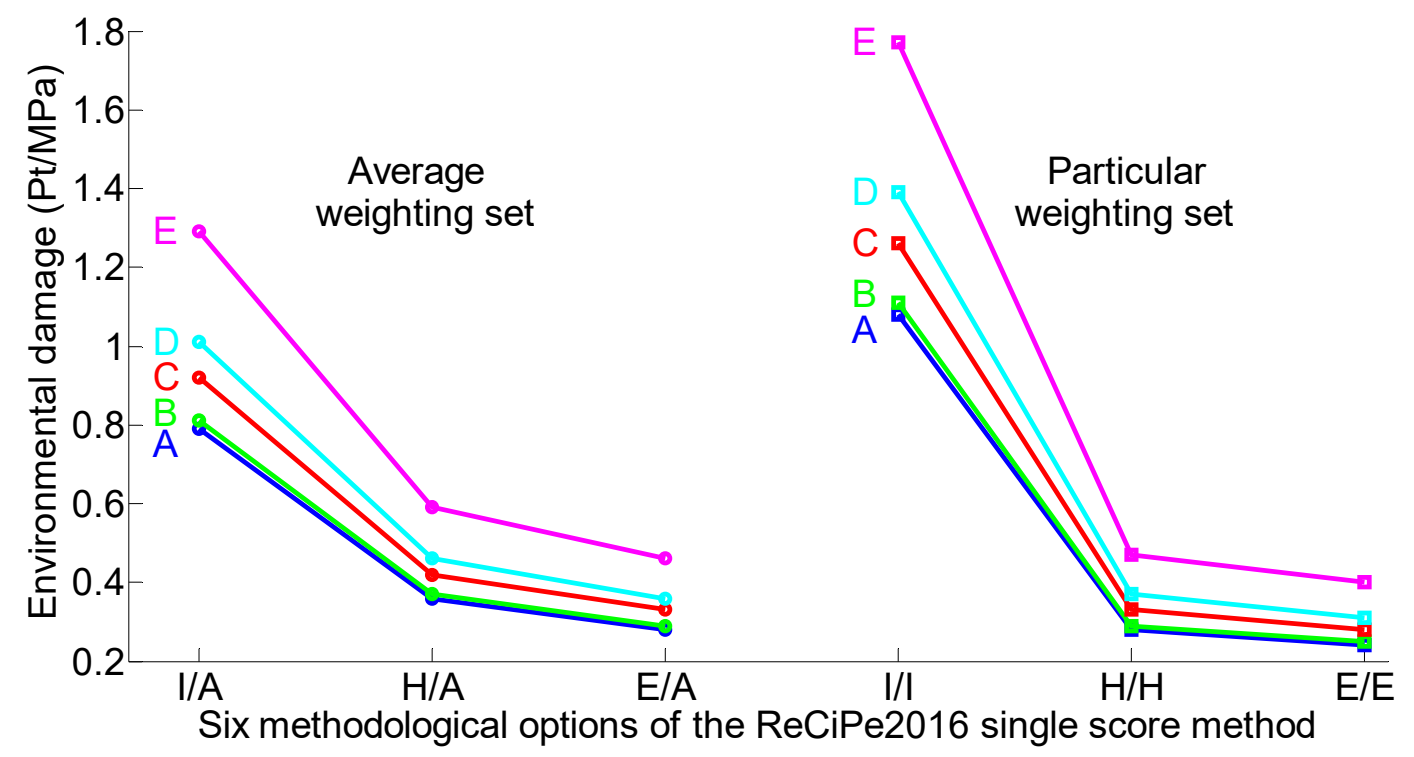

Figure 9. The environmental impacts of replacing sand with furnace coal bottom-ash (FBA) in CON-fix-W/C-0.55 concretes. A: FBA0 ${ }_{W / C 0.55}$; B: FBA30W/C0.55; C: FBA50 W/C0.55; D: FBA70 W/C0.55; E: FBA100 $\mathrm{W} / \mathrm{C} 0.55$. The functional unit (FU) was $1 \mathrm{~m}^{3}$ of concrete normalized to the 28-day concrete compressive strength. The life-cycle assessments (LCAs) (production stage) were evaluated via the six methodological options of the ReCiPe2016 single-score method.

The analysis of the CON-fix-W/C-0.45 concretes (Table 11) showed negative differences between $\mathrm{FBAO}_{\mathrm{W} / \mathrm{C} 45}$ and FBA70 ${ }_{\mathrm{W} / \mathrm{C} 45}$ and between $\mathrm{FBA} 30_{\mathrm{W} / \mathrm{C} 45}$ and $\mathrm{FBA} 50_{\mathrm{W} / \mathrm{C} 45}(\mathrm{P}=0.8653$ and $\mathrm{P}=0.1725$, respectively). Judgment was suspended between $\mathrm{FBA} 0_{\mathrm{W} / \mathrm{C} 45}$ and $\mathrm{FBA} 30_{\mathrm{W} / \mathrm{C} 45}$ and between $\mathrm{FBA} 0_{\mathrm{W} / \mathrm{C} 45}$ 
and FBA50 $0_{\mathrm{W} / \mathrm{C} 45}(\mathrm{P}=0.0181$ and $\mathrm{P}=0.0187$, respectively). The differences between all remaining pairs were found to be positive $(0.0101 \leq \mathrm{P} \leq 0.0143)$.

Table 11. P-values of the differences in single-score evaluation between pairs of CON-fix-W/C-0.45 concretes for the life-cycle assessment (LCA) (production stage) of $1 \mathrm{~m}^{3}$ of concrete normalized to the 28-day concrete compressive strength. The LCAs were evaluated via the six ReCiPe2016 single-score methodological options.

\begin{tabular}{cccccc}
\hline Concrete & FBA0 $_{W / C 0.45}$ & FBA30 $_{W / C 0.45}$ & FBA50 $_{W / C 0.45}$ & FBA70 $_{W / C 0.45}$ & FBA100 $_{W / C 0.45}$ \\
\hline FBA0 $_{W / C 0.45}$ & $\mathrm{X}$ & 0.0181 & 0.0187 & 0.8653 & $\mathbf{0 . 0 1 0 1}$ \\
FBA30 $_{\mathrm{W} / \mathrm{C} 0.45}$ & & $\mathrm{X}$ & 0.1725 & $\mathbf{0 . 0 1 1 3}$ & $\mathbf{0 . 0 0 2 4}$ \\
$\mathrm{FBA}_{\mathrm{W} / \mathrm{C} 0.45}$ & & & $\mathrm{X}$ & $\mathbf{0 . 0 1 4 3}$ & $\mathbf{0 . 0 0 2 2}$ \\
$\mathrm{FBA70}_{\mathrm{W} / \mathrm{C} 0.45}$ & & & & $\mathrm{X}$ & $\mathbf{0 . 0 0 6 9}$ \\
FBA100 & & & & $\mathrm{X}$ \\
\hline
\end{tabular}

Notes: Bold font: a positive difference was found between the compared concretes; Ordinal font: a negative difference was found between the compared concretes; Italic font: judgment was suspended regarding the difference between the compared concretes.

The analysis of the CON-fix-W/C-0.55 concretes (Table 12) showed negative differences between $\mathrm{FBA}_{\mathrm{W} / \mathrm{C} 0.55}$ and FBA30 $3 / \mathrm{C} 0.55$ and between $\mathrm{FBA} 30_{\mathrm{W} / \mathrm{C} 0.55}$ and FBA50 $/ \mathrm{W} / \mathrm{C} 0.55(\mathrm{P}=0.2543$ and $\mathrm{P}=$ 0.0242 , respectively). Judgment was suspended between $\mathrm{FBA} 0_{\mathrm{W} / \mathrm{C} 0.55}$ and $\mathrm{FBA} 50_{\mathrm{W} / \mathrm{C} 0.55}$ and between $\mathrm{FBA} 0_{\mathrm{W} / \mathrm{C} 0.55}$ and $\mathrm{FBA} 70_{\mathrm{W} / \mathrm{C} 0.55}(\mathrm{P}=0.0184$ and $\mathrm{P}=0.0295$, respectively). The differences between all remaining pairs were found to be positive $(0.0011 \leq \mathrm{P} \leq 0.0046)$.

Table 12. P-values of the differences in single-score evaluation between pairs of CON-fix-W/C-0.55 concretes for the life-cycle assessment (LCA) (production stage) of $1 \mathrm{~m}^{3}$ of concrete normalized to the 28-day concrete compressive strength. The LCAs were evaluated via the six ReCiPe2016 single-score methodological options.

\begin{tabular}{|c|c|c|c|c|c|}
\hline Concrete & $\mathrm{FBA0}_{\mathrm{W} / \mathrm{C} 0.55}$ & FBA30 6 W/C0.55 & $\mathrm{FBA}^{2} 0_{\mathrm{W} / \mathrm{C} 0.55}$ & FBA70 $_{W / C 0.55}$ & FBA100 ${ }_{W / C 0.55}$ \\
\hline $\mathrm{FBA}_{\mathrm{W} / \mathrm{C} 0.55}$ & $X$ & 0.2543 & 0.0184 & 0.0046 & 0.0012 \\
\hline FBA30W/C0.55 & & $x$ & 0.0242 & 0.0046 & 0.0011 \\
\hline FBA50 $\mathrm{W} / \mathrm{C} 0.55$ & & & $x$ & 0.0295 & 0.0025 \\
\hline $\mathrm{FBA70}_{\mathrm{W} / \mathrm{C} 0.55}$ & & & & $x$ & 0.0022 \\
\hline $\mathrm{FBA} 100_{\mathrm{W} / \mathrm{C} 0.55}$ & & & & & $x$ \\
\hline
\end{tabular}

Notes: Bold font: a positive difference was found between the compared concretes; Ordinal font: a negative difference was found between the compared concretes; Italic font: judgment was suspended regarding the difference between the compared concretes.

Therefore, according to the rankings (Figures 8 and 9) and P-value analyses (Tables 11 and 12) of the LCA results, concretes $\mathrm{FBA} 0_{\mathrm{W} / \mathrm{C} 0.45}, \mathrm{FBA} 30_{\mathrm{W} / \mathrm{C} 0.45}, \mathrm{FBA} 50_{\mathrm{W} / \mathrm{C} 0.45}, \mathrm{FBA} 0_{\mathrm{W} / \mathrm{C} 0.55}, \mathrm{FBA} 30_{\mathrm{W} / \mathrm{C} 0.55}$, and FBA50 $/ \mathrm{W} / \mathrm{C} 0.55$ were found to have the lowest environmental impact, concretes $\mathrm{FBA} 70_{\mathrm{W} / \mathrm{C} 0.45}$ and FBA7 $0_{\mathrm{W} / \mathrm{C} 0.55}$ were found to have intermediate environmental impacts, and concretes FBA $100_{\mathrm{W} / \mathrm{C} 0.45}$ and $\mathrm{FBA} 100_{\mathrm{W} / \mathrm{C} 0.55}$ were found to have the highest environmental impact.

\section{Discussion}

The purpose of this study was to conduct LCAs of byproduct-based concretes in which sand had been substituted with FBA in the following amounts: 0, 30, 50, 70, and $100 \mathrm{wt} \%$. The LCAs of five concretes were evaluated, and the concretes were designed using the following two design methods: concretes with fixed slump ranges of 0-10 mm (CON-fix-SLUMP-0-10) and 30-60 mm (CON-fix-SLUMP-30-60); and concretes with fixed W/C ratios of 0.45 (CON-fix-W/C-0.45) and 0.55 (CON-fix-W/C-0.55). The environmental impacts of the concretes were determined using (i) the ReCiPe2016 midpoint $\mathrm{H}$ method and (ii) six methodological options of the ReCiPe2016 single-score method. 
Based on the comparative LCA results of the FBA-based CON-fix-SLUMP and CON-fix-W/C concretes, it is difficult to determine which concrete has the lowest environmental impact. As sand was gradually replaced with FBA in the CON-fix-SLUMP concretes (CON-fix-SLUMP-0-10 and CON-fix-SLUMP-30-60), the environmental impacts of the concretes decreased (Figures 2-5), whereas as sand was gradually replaced with FBA in the CON-fix-W/C concretes (CON-fix-W/C-0.45 and CON-fix-W/C-0.55), the environmental impacts of the concretes increased (Figures 6-9).

The analysis of the CON-fix-W/C concretes confirmed the results of [18], who designed byproduct-based concretes (CS was used as a byproduct) with fixed $\mathrm{W} / \mathrm{C}$ ratios and recommended replacing sand with CS at up to $40 \mathrm{wt} \%$. In the present study, we also recommended a similar percentage - up to $50 \mathrm{wt} \%$ - of sand replacement with FBA.

In contrast to the replacement of sand with byproducts, replacing cement with byproducts mainly yields environmental benefits. Crossin [31] substituted 30\% of cement with slag, and observed a decrease in greenhouse gas emissions of $47.5 \%$ compared with conventional concrete. Saade et al. [5] substituted $66 \%$ of cement with slag, and observed a decrease in abiotic depletion, acidification, and eutrophication of $40-70 \%$. Hossain et al. [2] substituted $25 \%$ of cement with FA, and observed a reduction in the level of respiratory inorganics; global warming, e.g., $\mathrm{CO}_{2}$ emissions; nonrenewable energy; and acidification of $20 \%$, compared to conventional concrete.

Such inconsistencies in the environmental benefits of replacing sand or cement with byproducts can be associated with the different contributions from sand (0.3-2\%) and cement (74-93\%) to the total LCA of byproduct-based concretes [32,33]. The fact that sand makes such a small contribution to the total environmental impact of concrete means that the concrete design method (i.e., the fixed-slump or fixed W/C ratio methods) is a critical issue, with the choice of method affecting the results of the LCAs of the byproduct-based concretes.

In addition to the concrete design method, other factors contribute to the LCAs of the byproduct-based concretes, such as the byproduct modeling approaches (attributional or consequential) and the transportation distances (short or long). Turk et al. [16] conducted consequential modeling of foundry sand or steel slag and confirmed their environmental benefits when used in concrete. Additionally, Prem et al. [17] conducted attributional modeling of the use of CS in concrete, and confirmed that it had a negative environmental impact. With respect to transportation, Turk et al. [16] studied the impact of different distances for the delivery of byproducts to the concrete batch plant, and found that environmental benefits were obtained for short distances (up to $100 \mathrm{~km}$ ) and environmental damages were obtained for long distances (more than $100 \mathrm{~km}$ ).

\section{Conclusions}

Replacing sand with FBA in concrete is an active research issue. In this study, we investigated the environmental impacts of such replacement for two types of concrete: concrete with fixed slump ranges (0-10 $\mathrm{mm}$ and $30-60 \mathrm{~mm})$; and concrete with fixed $\mathrm{W} / \mathrm{C}$ ratios $(0.45$ and 0.55$)$. The following conclusions can be drawn:

1. Based on the ReCiPe2016 midpoint $\mathrm{H}$ method, the increasing substitution of sand with FBA in the byproduct-based concretes (30, 50, 70, and $100 \mathrm{wt} \%$ of sand replaced with FBA) led to (i) lower values of global warming potential, terrestrial ecotoxicity, water consumption, and fossil resource scarcity in the concretes with a fixed slump range, and (ii) higher values of the same four parameters in the concretes with fixed $\mathrm{W} / \mathrm{C}$ ratios;

2. Based on the six methodological options of the ReCiPe2016 single-score method, the following can be concluded: (i) for the concretes with a fixed slump range, the concretes with 50, 70, and $100 \mathrm{wt} \%$ of sand replacement caused the least environmental damage, whereas the concretes with 0 and $30 \mathrm{wt} \%$ of sand replacement caused the most environmental damage; (ii) for the concretes with a fixed W/C ratio, the concretes with 0,30 , and $50 \mathrm{wt} \%$ of sand replacement caused the least environmental damage, the concrete with $70 \mathrm{wt} \%$ of sand replacement caused intermediate 
environmental damage, and the concrete with $100 \mathrm{wt} \%$ of sand replacement caused the most environmental damage.

Therefore, the environmental benefit of replacing sand with FBA in concrete is variable, since the LCA results are highly dependent on the concrete design method. In the future, the attributional and consequential modeling of byproducts should be considered to further clarify the environmental effects of replacing sand with FBA byproducts from electricity production in concrete.

\section{Contributions}

The concrete industry produces concretes in which sand has been replaced with byproducts from other industries. As well as $\mathrm{CO}_{2}$ emissions controlling the fresh and hardened properties of such concretes, the industry also needs to consider their environmental impact. This paper confirms the necessity of performing environmental evaluations for each particular concrete design method (fixed slump range or fixed W/C ratio) due to the possibility of different (beneficial or harmful) environmental impacts.

\section{Limitations}

Three main limitations of this study are recognized. The first is the number of byproducts that were used. To better understand the environmental consequences of replacing sand with byproducts from other industries, additional byproducts, such as slag, stone dust powder, and phosphate waste, should be analyzed in further research.

The second limitation is the lack of an optimization approach for the LCA of byproduct-based concretes. Meng et al. [4] suggested an optimization mix design method for UHPC in which a high volume of cement was replaced with FAC, GGBS, and SF, and quartz sand was replaced with conventional concrete sand. According to this method, a wide range of concrete mixtures should be narrowed by the optimization of binder combinations, the W/C ratio, sand combination, the paste/sand volume ratio, and the steel fiber volume in order to ensure different fresh and hardened properties of the concretes, such as flowability, rheological properties, and compressive strength; then, the narrowed optimal set of design mixtures should be evaluated using the cost performance [4]. This optimization method was also used by Meng and Khayat [34], who added nanomaterials (graphite nanoplatelets and carbon nanofibers) to the mixture optimized by Meng et al. [4] to improve the cracking resistance and the fracture toughness of the UHPC. Therefore, future research should consider using this optimization method to evaluate the environmental impacts of byproduct-based concretes.

The third limitation of this study is the lack of consideration of service life in the LCA of byproduct-based concretes. Recently, Coppola et al. [35] suggested the use of an Empathetic Added Sustainability Index (EASI) to evaluate the environmental performance of byproduct-based concretes. According to this method, in addition to the production stage of the concretes, their service life (measured with performances such as bond to reinforcing steel, shrinkage, and shear properties) also needs to be considered when determining the concretes' environmental impacts [35]. Therefore, future researchers should consider using EASI to predict the LCA of byproduct-based concretes.

Funding: This research received no external funding.

Conflicts of Interest: The authors declare no conflicts of interest.

\section{References}

1. De Schepper, M.; Van den Heede, P.; Van Driessche, I.; De Belie, N. Life cycle assessment of completely recyclable concrete. Materials 2014, 7, 6010-6027. [CrossRef] [PubMed]

2. Hossain, M.U.; Poon, C.S.; Dong, Y.H.; Xuan, D.X. Evaluation of environmental impact distribution methods for supplementary cementitious materials. Renew. Sustain. Energy Rev. 2018, 82, 597-608. [CrossRef]

3. Phul, A.A.; Memon, M.J.; Shah, S.N.R.; Sandhu, A.R. GGBS and fly ash effects on compressive strength by partial replacement of cement concrete. Civ. Eng. J. Tehran 2019, 5, 913-921. [CrossRef] 
4. Meng, W.; Valipour, M.; Khayat, K.H. Optimization and performance of cost-effective ultra-high performance concrete. Mater. Struct. 2017, 50, 29. [CrossRef]

5. Saade, M.R.M.; da Silva, M.G.; Gomes, V. Appropriateness of environmental impact distribution methods to model blast furnace slag recycling in cement making. Resour. Conserv. Recycl. 2015, 99, 40-47. [CrossRef]

6. Kou, S.C.; Poon, C.S. Properties of concrete prepared with crushed fine stone, furnace bottom ash and fine recycled aggregate as fine aggregates. Construct. Build. Mater. 2009, 23, 2877-2886. [CrossRef]

7. Chowdhury, R.; Apul, D.; Fry, T. A life cycle based environmental impacts assessment of construction materials used in road construction. Resour. Conserv. Recycl. 2010, 54, 250-255. [CrossRef]

8. Kua, H.W. The consequences of substituting sand with used copper slag in construction-An embodied energy and global warming potential analysis using life cycle approach and different allocation methods. J. Ind. Ecol. 2013, 17, 869-879. [CrossRef]

9. Lim, S.K.; Tan, C.S.; Li, B.; Ling, T.C.; Hossain, M.U.; Poon, C.S. Utilizing high volumes quarry wastes in the production of lightweight foamed concrete. Construct. Build. Mater. 2017, 151, 441-448. [CrossRef]

10. Zhang, B.; Poon, C.S. Internal curing effect of high volume furnace bottom ash (FBA) incorporation on lightweight aggregate concrete. J. Sustain. Cem. Based Mater. 2017, 6, 366-383. [CrossRef]

11. Skalny, J.P. Questions to Arnon Bentur, head, National Building Research Institute, Technion, Israel Institute of Technology, Haifa. Adv. Cem. Based Mater. 1996, 3, 81-85. [CrossRef]

12. The Israel Electric Corporation Ltd. Financial Reports for the Nine and Three Months Ended September 30; The Israel Electric Corporation Ltd.: Haifa, Israel, 2016; pp. 1-191.

13. Lieberman, R.N.; Knop, Y.; Querol, X.; Moreno, N.; Muñoz-Quirós, C.; Mastai, Y.; Anker, Y.; Cohen, H. Environmental impact and potential use of coal fly ash and sub-economical quarry fine aggregates in concrete. J. Hazard. Mater. 2018, 344, 1043-1056. [CrossRef] [PubMed]

14. Heijungs, R.; Guinée, J.B. Allocation and 'what-if' scenarios in life cycle assessment of waste management systems. Waste Manag. 2007, 27, 997-1005. [CrossRef] [PubMed]

15. ISO 14040 (International Organization for Standardization). Environmental Management Life Cycle Assessment Principles and Framework; International Organization for Standardization: Geneva, Switzerland, 2006.

16. Turk, J.; Cotič, Z.; Mladenovič, A.; Šajna, A. Environmental evaluation of green concretes versus conventional concrete by means of LCA. Waste Manag. 2015, 45, 194-205. [CrossRef] [PubMed]

17. Prem, P.R.; Verma, M.; Ambily, P.S. Sustainable cleaner production of concrete with high volume copper slag. J. Clean. Prod. 2018, 193, 43-58. [CrossRef]

18. Gursel, A.P.; Ostertag, C. Life-cycle assessment of high-strength concrete mixtures with copper slag as sand replacement. Adv. Civ. Eng. 2019, 2019, 6815348. [CrossRef]

19. Bai, Y.; Darcy, F.; Basheer, P.A.M. Strength and drying shrinkage properties of concrete containing furnace bottom ash as fine aggregate. Construct. Build. Mater. 2005, 19, 691-697. [CrossRef]

20. ISO 13315-1 (International Organization for Standardization). Environmental Management for Concrete and Concrete Structures 2012, Part 1: General Principles; International Organization for Standardization: Geneva, Switzerland, 2012.

21. Habert, G.; de Lacaillerie, J.B.D.; Roussel, N. An environmental evaluation of geopolymer based concrete production: Reviewing current research trends. J. Clean. Prod. 2011, 19, 1229-1238. [CrossRef]

22. Brand, S. How Buildings Learn; Viking Press: New York, NY, USA, 1994.

23. Gursel, A.P.; Masanet, E.; Horvath, A.; Stadel, A. Life-cycle inventory analysis of concrete production: A critical review. Cem. Concr. Compos. 2014, 51, 38-48. [CrossRef]

24. Napolano, L.; Menna, C.; Asprone, D.; Prota, A.; Manfredi, G. Life cycle environmental impact of different replacement options for a typical old flat roof. Int. J. Life Cycle Assess. 2015, 20, 694-708. [CrossRef]

25. SimaPro, Version 9.0; PRé Consultants: Amersfoort, The Netherlands, 2019.

26. Thompson, M.; Ellis, R.; Wildavsky, A. Political cultures. In Cultural Theory; Westview Press: Boulder, CO, USA, 1990.

27. Huijbregts, M.A.J.; Steinmann, Z.J.N.; Elshout, P.M.F.; Stam, G.; Verones, F.; Vieira, M.; Zijp, M.; Hollander, A.; van Zelm, R. ReCiPe2016: A harmonised life cycle impact assessment method at midpoint and endpoint level. Int. J. Life Cycle Assess. 2017, 22, 138-147. [CrossRef]

28. Pushkar, S. Modeling the substitution of natural materials with industrial byproducts in green roofs using life cycle assessments. J. Clean. Prod. 2019, 227, 652-661. [CrossRef] 
29. Picquelle, S.J.; Mier, K.L. A practical guide to statistical methods for comparing means from two-stage sampling. Fish. Res. 2011, 107, 1-13. [CrossRef]

30. Hurlbert, S.H.; Lombardi, C.M. Final collapse of the Neymane-Pearson decision theoretic framework and rise of the neoFisherian. Ann. Zool. Fennici 2009, 46, 311-349. [CrossRef]

31. Crossin, E. The greenhouse gas implications of using ground granulated blast furnace slag as a cement substitute. J. Clean. Prod. 2015, 95, 101-108. [CrossRef]

32. Celik, K.; Meral, C.; Gursel, A.P.; Mehta, P.K.; Horvath, A.; Monteiro, P.J.M. Mechanical properties, durability, and life-cycle assessment of self-consolidating concrete mixtures made with blended Portland cements containing fly ash and limestone powder. Cem. Concr. Compos. 2015, 56, 59-72. [CrossRef]

33. Gursel, A.P.; Ostertag, C.P. Impact of Singapore's importers on life-cycle assessment of concrete. J. Clean. Prod. 2016, 118, 140-150. [CrossRef]

34. Meng, W.; Khayat, K.H. Mechanical properties of ultra-high-performance concrete enhanced with graphite nanoplatelets and carbon nanofibers. Compos. B Eng. 2016, 107, 113-122. [CrossRef]

35. Coppola, L.; Coffetti, D.; Crotti, E.; Gazzaniga, G.; Pastore, T. An Empathetic Added Sustainability Index (EASI) for cementitious based construction materials. J. Clean. Prod. 2019, 220, 475-482. [CrossRef]

(C) 2019 by the author. Licensee MDPI, Basel, Switzerland. This article is an open access article distributed under the terms and conditions of the Creative Commons Attribution (CC BY) license (http://creativecommons.org/licenses/by/4.0/). 